Archived version from NCDOCKS Institutional Repository http://libres.uncg.edu/ir/asu/

\title{
Appalachïan
}

B O O N E, NORT H C A R O L I A

\section{Positioning Within A Cultural Context: Using Ricoeur's Preunderstandings As A Heuristic For Narrative Data Analysis In Exploring Identity, Structure, And Agency}

\author{
By: Rachel E. Wilson
}

\begin{abstract}
I argue that Ricoeur's preunderstandings can be used as a heuristic to aid researchers who collect narratives as data (1) to identify cultural meanings that become resources for participants' positioning work, (2) to ground the identified cultural meanings in participants' experiences, and (3) to understand participants' interpretations of constraint and agency within that context. I outline how the philosophical hermeneutics of Ricoeur is consistent with a sociocultural perspec- tive on positioning and identity, as well as present data analysis questions developed from Ricoeur's ideas of narrative configuration to explore common cultural meanings used by participants in interpreting their lived experience. These questions provide a strategy to examine how participants may be referring to common cultural meanings but their individual interpretations of these meanings can have different implications for their feelings of agency.
\end{abstract}

Rachel E. Wilson (2015). Positioning within a cultural context: using Ricoeur's preunderstandings as a heuristic for narrative data analysis in exploring identity, structure, and agency, International Journal of Qualitative Studies in Education, 28:8, 887-905, DOI: 10.1080/09518398.2014.948097. Publisher version of record available at: https://doi.org/10.1080/09518398.2014.948097 


\title{
Positioning within a cultural context: using Ricoeur's preunderstandings as a heuristic for narrative data analysis in exploring identity, structure, and agency
}

\author{
Rachel E. Wilson* \\ Department of Curriculum and Instruction, Reich College of Education, \\ Appalachian State University, Boone, NC, USA
}

\begin{abstract}
I argue that Ricoeur's preunderstandings can be used as a heuristic to aid researchers who collect narratives as data (1) to identify cultural meanings that become resources for participants' positioning work, (2) to ground the identified cultural meanings in participants' experiences, and (3) to understand participants' interpretations of constraint and agency within that context. I outline how the philosophical hermeneutics of Ricoeur is consistent with a sociocultural perspective on positioning and identity, as well as present data analysis questions developed from Ricoeur's ideas of narrative configuration to explore common cultural meanings used by participants in interpreting their lived experience. These questions provide a strategy to examine how participants may be referring to common cultural meanings but their individual interpretations of these meanings can have different implications for their feelings of agency.
\end{abstract}

Keywords: hermeneutics; narrative; Ricoeur

\section{Introduction}

In a study exploring the influence of cultural context on the interpretations of female first-generation college students as science majors, I interviewed two participants who shared very similar demographic information, yet their interpretations of their persistence toward their academic goals in science were very different (Wilson \& Kittleson, 2013). These young women positioned themselves differently, as persistent or not, based on their interpretations of the events in their lived experience. In order to understand this difference in interpretation, I analyzed their narratives of their lived experiences in and out of school. By narratives, I mean the specifically textual data either written or transcribed from audio that is "thematically organized by plots" (Polkinghorne, 1995, p. 5). I wanted to analyze these narratives to tease out the culturally available understandings within a particular context that students were using to make sense of their own persistence in the field of science. In paying attention to the power of the cultural narratives that these women were referring to and using to evaluate and interpret their experiences, I aimed to analyze how they positioned themselves vis-à-vis the cultural narratives and the implications for their feelings of persistence. For more detailed information about the purpose of the study and the results of this analysis, please see Wilson and Kittleson (2013).

*Email: wilsonre3@appstate.edu 
When I looked to other sociocultural qualitative researchers for guidance on how to analyze narrative data to tease out cultural narratives, I could not find sufficiently detailed explanations that allowed me to think about how to approach data analysis. Polkinghorne $(1988,1995)$ has advocated analyzing narratives to explore the interpretations of lived experience and has used Ricoeur's (1984, 1992) philosophical writings on narrative as a basis for his arguments. Yet Polkinghorne $(1988,1995)$ and other narrative researchers (Austin \& Carpenter, 2008; Hole, 2007) either do not outline specific data analysis strategies to analyze narratives or lack detail in their data analysis methods for analyzing narrative data. In addition, I found a lack of reference to specific data analysis strategies for analysis of narratives in qualitative studies examining either the influence of cultural context on positioning in education (Bartlett, 2007; Jupp \& Slattery, 2010; Niesz, 2008) and in science education (Carlone, 2004; Johnson, 2007). These researchers either do not distinguish between data analysis methods for narrative and non-narrative data (Carlone, 2004; Johnson, 2007) or do not include specific information about their data analysis methods (Bartlett, 2007; Jupp \& Slattery, 2010; Niesz, 2008). Other researchers who have explored the influences of race and class on the experiences of first-generation college students through in-depth interviews with participants have not described specific analysis methods for narrative and non-narrative data from interview transcripts (Orbe, 2004; Stuber, 2011). Therefore, I was left without an understanding as to how these researchers moved from narrative data to conclusions about their narrative data.

In the absence of models within the narrative research and sociocultural qualitative research literature for analysis of narratives, I decided to go back to theory underlying narrative construction in order to develop a strategy that would help me to identify culturally available understandings. Polkinghorne's (1988, 1995) work was instrumental in the design of my data collection, but because he did not outline data analysis methods, I went to his source: Ricoeur. Ricoeur's (1984, 1988) writings on the configuration of narratives and the implications for narrating identity $(1988,1992)$ are the foundation of the data analysis strategy that I developed. Therefore, the purpose of this article is to highlight the ways in which Ricoeur's (1984, 1988) writings can enrich research on cultural narratives and narrative identity. I argue that Ricoeur's preunderstandings (1984) can be used as a heuristic to aid researchers who collect narratives as data (1) to identify cultural meanings that become resources for participants' positioning work, (2) to ground the identified cultural meanings in participants' experiences, and (3) to understand participants' interpretations of constraint and agency within that context.

Based on the philosophical hermeneutics of Paul Ricoeur (1984, 1988, 1992), I developed questions for analysis of narrative data from in-depth interviews in order to focus on the cultural resources that the participants were using to evaluate their experiences. In this article, I first outline the philosophical hermeneutic ideas of Ricoeur and argue that these ideas are consistent with a sociocultural perspective on positioning and identity. I then present the data analysis questions I developed from Ricoeur's (1984, 1988, 1992) writing and demonstrate how these were used to analyze one participant's narratives. In addition, I conclude by discussing how these questions can be used as a heuristic for analysis of narratives in sociocultural qualitative research. 


\section{Ricoeur's philosophical hermeneutics}

\section{Hermeneutics}

As a philosophical foundation for qualitative research, philosophical hermeneutics does not give more primacy to the author or the reader, but instead focuses on the interpretations developed in dialogue between the text and the reader (Freeman, 2007). Philosophical hermeneutics is associated with the work of Gadamer and Heidegger. Heidegger writes that interpretation is our way of being in the world, and Gadamer, working from Heidegger's ideas, argues that language "is universal and forms the universe in that all understanding and human existence occur within it" (Grondin, 1994, p. 122). Language, as a form of communication, is "universal" in that humans use language to describe and capture our experiences in the world in words. The language we use to describe something is a product of a social context. Meanings are associated with the language we use to describe our experiences (Polkinghorne, 1988). Gadamer argued that it is only through open dialogue between people that we are able to understand more deeply the meanings being conveyed through language (Grondin, 1994). Therefore, research that uses philosophical hermeneutics as a foundation for social research is concerned with understanding how people make meaning from their experiences in the world by analyzing the language they use (Polkinghorne, 1988, p. 159). Using philosophical hermeneutics as a methodological foundation for this research, therefore, encouraged me to focus on my participants' meanings of their lived experience as well as the sociocultural influences on those meanings, rather than pre-identified meanings from the researcher(s) and/or research literature (Austin \& Carpenter, 2008).

\section{Ricoeur's philosophy on narrative}

Ricoeur's ideas about the nature of narrative and narrating as a meaning-making practice are influenced by philosophical hermeneutics. Ricoeur (1984) argues that the act of stringing together events into a narrative - called configuration or mimesis m $_{2}$ is a hermeneutic act. Ricoeur (1984) describes configuration as a mediating event in a dialogue between the author and the audience for which the author is writing. Ricoeur (1984) writes that people construct narratives of the events in their lives much like a historian constructs a narrative. "By narrating a life of which I am not the author as to existence, I make myself its coauthor as to its meaning" (Ricoeur, 1992, p. 162). Participants have access to events in their lives, actual events, but in putting them together in a coherent structure in an answer to a question, they are involved in configuring those events much like an author in attempting to create a unified meaning. Ricoeur (1984) writes, "every narrative explains itself, in the sense that to narrate what has happened is already to explain why it happened" (p. 154). When we choose which events to include or exclude in a narrative, which details are important or irrelevant, and how to convey to our listeners why or how events came to happen, we are presenting particular meanings about those events to our listeners. Therefore, in constructing a narrative, the participant gives meaning to the events in the explanation of why the events transpired, transpire, or will transpire.

The author, in configuration, must figure out how separate events fit together into a meaningful narrative. Narratives reveal how we think about events and their relationship to each other in time. Configuration shows our interpretations of our temporal experience. This act of mimesis, of configuration of a narrative, is 
composed of three parts: prefiguration, configuration, and refiguration (Ricoeur, 1984). Prefiguration requires of the author a "preunderstanding of the world of action, its meaningful structures, its symbolic resources, and its temporal character. These features are described rather than deduced" (Ricoeur, 1984, p. 54). These preunderstandings that narrators draw upon in constructing their narratives give the listener, or reader as Ricoeur (1984) says, clues about the sociocultural and historical context in which the narrator is constructing their narrative, but also focus on how an author "reckons with time" (p. 62). Each of the three elements of prefiguration is discussed below.

\section{Structural elements}

The meanings that individuals attribute to events are not solely subjective. Ricoeur (1984) argues that narratives spring forth from cultural systems that have influences on the way in which narratives are authored. Authors have to work within contexts that influence how they configure their narratives and, based on his or her lived experience in a society, will construct narratives that reflect their knowledge of cultural meanings that exist amongst the members of that society. These cultural meanings Ricoeur (1984) refers to as preunderstandings, or practical understandings. Ricoeur (1984) discusses three major features of preunderstandings. The first involves the structural elements of a narrative: (1) goals, (2) motives, (3) agents, (4) circumstances, (5) interactions, and (6) outcomes (Ricoeur, 1984, p. 55). Ricoeur (1984) argues that a narrative is a plot, a stringing together of a set of events in a structure that gives meaning to those events. The structural elements of a narrative are examples of preunderstandings that reflect the cultural framework within which the narrative is authored. While these elements are pieces of any narrative, the possible goals, motives, etc., reflect a practical understanding of the types of goals, motives, etc., that are culturally meaningful or significant. For example, in the story of Cinderella, her stepsisters' shared goal is to marry the prince. Because of this goal, they have a motive to keep Cinderella away from meeting the prince. A set of circumstances occur in the story which allow Cinderella to interact with the prince, and so the outcome of the story is that she marries the prince instead of either of her stepsisters. This fairy tale has all of the structural elements of a narrative and reflects possible goals, motives, and agents that were culturally meaningful in the society and time period in which it was written.

\section{Symbolic elements}

In addition to preunderstandings about structural elements of narratives, people draw on symbolic resources, or culturally available meanings, in explaining and evaluating the events in a narrative. These preunderstandings of symbolic resources relate to what Ricoeur (1984) describes as "signs, rules, and norms" which are cultural meanings used in constructing a narrative because of the "public character of any meaningful articulation" (p. 57). Symbolic resources, then, are meanings that are available within a context, as narratives are constructed within a cultural framework (Ricoeur, 1984). Cultural meanings are available within a context as interpretations, as they provide both literal and figurative understandings. People make judgments about people and events in making sense of their own experiences based on these cultural meanings. For example, in the 
case of Cinderella, the goal of marriage and its importance to women reflect a cultural meaning that women were worth less if they were unmarried. In addition, the strong motive to marry not just any man, but a prince, reflects a cultural meaning that the status of a woman is dependent upon the status of her husband. These cultural meanings in the narrative of Cinderella reflect the culture of the society during the time period in which it was written.

\section{Temporal elements}

Ricoeur's (1984) third major feature of preunderstandings is that they are temporal in nature. Ricoeur (1984) discusses Augustine's assertion in Confessions that human souls experience time as a threefold present, rather than describing time as having to do with specific measurements relating to the movement of celestial bodies. The idea of the threefold present is about the soul experiencing the present not as the passive processing of impressions, but as actively attending to their experiences in a state of distended time, distentio animi. This experience of the present as distended (as including the past in the form of memories and the future in the form of expectations) is the threefold present: "by entrusting to memory the fate of things past, and to expectation that of things to come, we can include memory and expectation in an extended and dialectical present" (Ricoeur, 1984, p. 11). Ricoeur suggests that our experience of time is always in relation to things in our past and our future, to things that have happened in the past, and things that we expect to happen in the future. Therefore, in constructing narratives of lived experience, Ricoeur (1984) writes that we do not passively experience the present as the present alone, but are always comparing our present experiences to experiences that have come before and that we expect to come after. This experience of time as a threefold present Ricoeur (1984) relates to Heidegger's conception of within-time-ness. Ricoeur (1984) emphasizes that narrators "reckon with time" in constructing a narrative and that looking for evidence of reckoning with time gives the reader an idea of what meaning the narrator gives to events based on how they connect them in time (p. 62). For example, a narrative could be as short as: I got in a boat. First, I leaned over the side of the boat. Then the boat tipped over. The reader assumes that the person leaning over the side of the boat is the cause of the boat tipping over because of the order of the sentences, but also because of the use of temporal indicators, such as the words first and then. If another time word such as next was used in a sentence before the word then, the reader may choose to change the cause of the boat tipping over, as in: I got in a boat. First, I leaned over the side of the boat. Next, I grabbed the edge of the boat to regain my balance. Then the boat tipped over.

Therefore, in his explanations of how configuration, or mimesis ${ }_{2}$, is a hermeneutic act, Ricoeur (1984) distinguishes his philosophy from others because of its purpose in addressing the meaning of text being mediated by both the author and readers in their attention to structural, symbolic, and temporal elements. "For a semiotic theory, the only operative concept is that of the literary text. Hermeneutics, however, is concerned with reconstructing the entire arc of operations by which practical experience provides itself with works, authors, and readers" (Ricoeur, 1984, p. 53). Ricoeur's (1984) inclusion of Heidegger's ideas about the experience of time as "within-time-ness" and Augustine's threefold present are what 
differentiate his theory of narrative construction and its relationship to meaning from the focus of discourse analysis. Gee (1999) discusses the purpose of discourse analysis as an exploration of "language-in-use" to tease out how grammar and sentence structure can influence our understandings of individuals' ways of "saying, doing, and being in the world" (p. 8). Discourse analysis as a theory and method of research thus is concerned with the meaning that the researcher discovers in the language used by others, whereas Ricoeur's $(1984,1988)$ hermeneutic theory of narrative is concerned with how meaning is mediated through the construction of a narrative in relation to an experience of time.

\section{Positioning}

In addition to interpreting meanings of lived experiences, narratives also include interpretations of the author's position, or place, within science and society. Ricoeur (1992) describes how we come to understand meanings of our positions, or roles related to our identity, gradually through social interactions with more experienced members, much like an apprentice learns a tradition by following the lead of someone more expert: "constitutive rules, however, come from much further back than from any solitary performer; it is from someone else that the practice of a skill, a profession, a game, or an art is learned" (p. 156). Ricoeur (1992) explains that learning these practical rules is not the only source of meaning to be found in a context; meanings also come from larger contexts. Studying how participants narrate their experiences, therefore, can elucidate how they interpret their positions or roles within a cultural context. This ascription of positions or roles Ricoeur (1992) describes as an interpretive event related to identity. In ascribing qualities to a person (or to ourselves), we make judgments about how we are the same as (or not the same as) someone else in relation to certain attributes. In narrating events, Ricoeur (1992) writes that we assign, or ascribe, to people roles in which there is often "an essential dissymmetry between the one who acts and the one who undergoes" ( $p$. 145). The experience of positioning, therefore, is an interpretative event that involves evaluating the differences in attributes associated with oneself and others.

Ricoeur (1988) argues that narratives are told because the narrative is the mediator of an individual or community's experience of time. Ricoeur (1984)

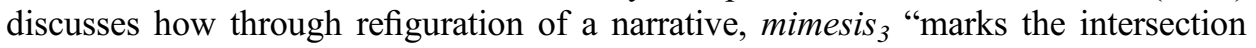
of the world of the text and the world of the hearer or reader; ... the world configured ... and the world wherein real action occurs and unfolds its specific temporality" (p. 71). In participants telling narratives about themselves and their lived experiences, they are refiguring their narrative identities. Ricoeur (1988) writes:

The theory of reading has warned us that the strategy of persuasion undertaken by the narrator is aimed at imposing on the reader a vision of the world that is never ethically neutral, but that rather implicitly or explicitly induces a new evaluation of the world and of the reader as well. (p. 249)

In participants narrating their experiences and identities, they are positioning themselves either in congruence with the way others identify them, or in resistance to the way others identify them. Thus, the act of an individual narrating his or her own lived experience is one of convincing themselves and their listener of their evaluation of their identity. 


\section{Narrative identity}

Ricoeur (1992) recognizes how practices in the day-to-day existence of an individual (basic actions and practices) influence meanings occurring within a social history of practices (practical field) and within a larger set of meanings available for making sense of life events (horizon of ideals and projects). These sets of meanings in a context exist at two levels: one grounded in daily, individual life and the other a product of collective storytelling. Ricoeur (1992) argues that people take meanings from both levels when they make sense of the events in their lives and their own identity.

Ricoeur (1992) argues that when a person creates a narrative of events in their life, they are also explaining who they are. Thus, in constructing narratives, people construct a narrative identity. When a person configures the events of their lives into a narrative, this person "produces a dialectic of the character which is quite clearly a dialectic of sameness and selfhood" (Ricoeur, 1992, p. 141). Ricoeur's (1992) ideas of sameness (idem) and selfhood (ipse) are related to aspects of a person in relation to the temporal permanence of these aspects of their character. Some aspects of a person's identity are always considered to be the same - they hold some permanence in identifying who we are - while other aspects of a person's identity are part of our present selves, aspects we have to choose to have identified as part of our character.

Ricoeur's (1988) theory of narrative construction explicitly connects narrative configuration with narrating identity:

As the literary analysis of autobiography confirms, the story of a life continues to be refigured by all the truthful or fictive stories a subject tells about himself or herself.

This refiguration makes this life itself a cloth woven of stories told. (p. 246)

Ricoeur (1988) emphasizes that in retelling a story about yourself to yourself or to others, you are refiguring your narrative identity, retelling who you are. This narrating of identity gives the author possibilities for reinforcing identity in addition to possibilities for changing how you identify with others. Thus, in configuring and refiguring narratives, the author has possibility for a dynamic narrative identity over time. If other individuals are narrating your identity in a different way, however, an individual may not be able to adequately refigure his or her self-narrative in resistance to this other narrative. Thus, using Ricoeur's (1988, 1992) writings opens up possibilities for analysis and discussions of the dynamic role of agency and structure as influences on narrative construction and narrative identity.

\section{Ricoeur and a sociocultural perspective on positioning and identity}

In this article, I have drawn attention to key ideas in Ricoeur's philosophy on the construction of narratives and narrative identity to show their potential as the foundation for a data analysis strategy to be used in interpretive qualitative research. Other researchers have discussed the use of Ricoeur as being consistent with philosophical hermeneutics and sociocultural research. For example, Ezzy (1998a) argues that the philosophical hermeneutics of Ricoeur and his views on narrative provide sociologists with an analytical framework for narrative research that is congruent with symbolic interactionism. Ezzy (1998a) highlights the usefulness of Ricoeur's ideas about the configuration of lived experience in highlighting the societal influence on narrative construction: "the narrative integration of lived experience 
and preexisting plots reflects the influence of power, social organization, and the "politics of storytelling"' (p. 250). Ezzy (1998b, 2000) emphasizes that using Ricoeur's philosophical hermeneutics as an analytical framework can help sociologists think about the socially available narrative structures and ways in which these structures influence how people make sense of their lived experiences. However, Ezzy (1998a, 1998b, 2000) does not discuss his use of Ricoeur in his own data analysis. Ricoeur's $(1984,1992)$ ideas about the configuration of narrative, however, are not only congruent with research that considers the socially/culturally available meanings influencing the individual narratives, but also how individuals give meaning to their experiences in response to socially/culturally available meanings.

The philosophical hermeneutic ideas of the social nature of language and meanings have also been taken up by anthropologists as they reckon with the definition of culture. Geertz's (1973) conception of culture, not as "a power," but as "a context" (p. 14) allows for the idea that people interpret their experiences within an available set of meanings. In discussing how post-modernism has troubled the idea of culture, Eisenhart (2001) argues that in a society that is increasingly affected by globalization, and thus, the permeability of cultures, anthropologists of education must view culture as produced within contexts, as providing a background against which people make meaning in daily practices. Holland, Lachicotte, Skinner, and Cain (1998) reiterate this idea that researchers should conceive of culture as a "socially ... constructed realm of interpretation" (p. 52) and a space that is permeable to the meanings that participants in that world bring to their social interactions. I argue that this is a hermeneutically influenced perspective of culture, as it places emphasis on socially constructed meanings in practice. People interpret and come to understandings within a set of meanings, rather than a fixed body of meanings existing somewhere outside of people. This hermeneutically influenced conception of culture fits with how Ricoeur (1984) envisions how people draw on their preunderstandings of their cultural world in the configuration of their narratives of their lived experiences.

Researchers have argued that using a sociocultural perspective on positioning and identity allows them "to better understand the resources for, and constraints upon, social action - the interplay of agency and structure" (Levinson \& Holland, 1996, p. 3). Ricoeur's (1984) ideas about the configuration of narratives as a meaning-making practice take into account how both structure (preunderstandings in narrative configuration) and agency (the act of configuration and refiguration) influence the construction and telling of narratives when he discusses the act of ascription. The act of ascription of the characteristics of others in relation to oneself as described by Ricoeur (1992) is related to the idea of positioning discussed by Holland and Leander (2004). Holland and Leander (2004) connect the idea of "positioning" to the dialectical tension between structure (available positions) and agency (individual subjectivities). Ricoeur (1992) describes ascription as an act that is always related to the actions of a person (whether these be motives or intentions) and whether or not a person has the power to act. "What, in fact, distinguishes ascription from the simple attribution of a predicate to a logical subject is the agent's power to designate herself by designating her other" (Ricoeur, 1992, p. 111). Therefore, in being ascribed certain characteristics by others, i.e. responding to stereotypes that relate to some aspect of their identity, participants respond to the position ascribed to them. 
Ascription, therefore, is like positioning, in that it "involves socially producing particular individuals and groups as culturally imagined types such that others and, even the person herself, at least temporarily, treat her as though she were such a person" (Holland \& Leander, 2004, p. 130). People respond to ascription by others because positioning by others requires a response: an assent or resistance. The act of positioning, or ascription of a role, of an identity, or a cultural understanding, becomes an opportunity for a person to assent or resist an interpretation. In narrating ascription or positioning events, participants assent or resist interpretations of their identity. For example, in resisting interpretations, participants give examples of events that support why they are not as others assume or their antagonistic reactions to such positioning.

Verhesschen (2003) discusses Ricoeur's ideas of narrative identity in a way that illustrates how his conception of identity is congruent with a sociocultural perspective on identity. Verhesschen (2003) writes that the narratives we tell about our lived experiences answer an implicit question: Who are you? Thus, Ricoeur's (1992) narrative identity is a "public identity," as the telling to an audience gives an author "constraints" on the type of story they can tell (p. 459). Participants tell stories about their lives and about themselves, but they do so in an "intersubjective context" because the telling involves both an author and an audience (Verhesschen, 2003, p. 460). This intersubjective context, therefore, illustrates the tension experienced by individuals between the power of the cultural context and the agency of the individual in making meaning of their lived experiences.

Using Ricoeur's $(1984,1988,1992)$ work on the construction of narrative and narrative identity as a foundation for data analysis of interpretive qualitative data of participants' lived experiences can help address issues discussed in education research about the lack of a clear definition of identity. Sfard and Prusak (2005) argue that the ways in which scholars such as Gee (2001) and Holland et al. (1998) define identity still leave unanswered "how one can decide 'who' or 'what kind of person' a given individual is" (p. 16). Sfard and Prusak (2005) propose that identity is the stories that individuals tell about themselves. Therefore, I believe that Ricoeur's (1984, 1988, 1992) philosophical writings on the construction of narratives and narrative identity - specifically the elements of preunderstandings and refiguration of narratives of identity - are a strong theoretical foundation for data analysis strategies addressing narratives of identity.

Studying the narratives of participants of their lived experiences not only can lead to a deeper understanding of their interpretations of the meanings available within their contexts, but can lead to multiple understandings of how these experiences become "heuristics" for future responses (Holland et al., 1998). "The competence to understand a series of episodes as part of our story informs our own decisions to engage in actions that move us toward a desired ending" (Polkinghorne, 1988 , p. 145). In examining the narratives of female first-generation students as science majors, I interpreted how cultural resources influenced participants' "genesis" of responses in action and how these responses in action are used as "heuristics for the next moment of activity" (Holland et al., 1998, p. 40). Therefore, the meaning that participants gave to their lived experience has implications for how they view what can and cannot happen in the future. Examining the meaning they give to events helps in interpreting what meanings participants are drawing on as heuristics for decisions about their futures in science. 


\section{Ricoeur's hermeneutics as methodology \\ Data collection}

In seeking to understand the influence of cultural understandings on the experiences of upwardly mobile females, I focused my data collection and analysis on 10 participants' narratives of their experiences elicited in in-depth interviews. I conducted three semi-structured interviews with each of the 10 participants throughout one university semester, using a three-interview format described by Seidman (2006) as a basis. Seidman (2006) describes the purpose of the three 90-minute interview format is to establish the context for participants' lived experiences, consisting of an initial life history interview, a second interview focused on day-to-day experiences as science majors, and a third interview focused on interpreting their experiences. In designing my interview questions and topics, I aimed to elicit the women's narratives of their experiences in science - inside and outside of school - and their goals. Sample questions used in semi-structured interviews to elicit narratives include:

- When did you first realize that you liked science?

- How did you decide that you wanted to go to college?

- Tell me about your decision to major in science.

- Some people have difficulty succeeding as science majors, while others succeed fairly easily. How would you describe your experience as a science major?

In eliciting narratives from these women about the events in their lives, I asked them to make sense of their lived experiences, and specifically related to their education in science.

\section{Data analysis}

In drawing on Ricoeur's (1984) philosophical hermeneutic ideas of how symbolic resources are preunderstandings used in narrative configuration in explaining and evaluating their experiences, I analyzed participants' interview transcripts to identify these culturally available meanings. The transcripts of the interview data contained the participants' narratives and were the texts that I analyzed. Their interpretations were bound up in the text, in the language that they brought to their experiences in order to describe them to me, their audience. Therefore, the interviews themselves are a hermeneutic conversation between each participant and me that I interpreted in order to more deeply understand the experiences of these women, both individually and collectively.

I re-read through each interview transcript and identified passages where participants narrated events related to persistence and positioning. Rather than extracting words, phrases, or lines of the interview transcripts to fit into the different element categories in a table, which would lead to a loss in coherence of the narrative, I analyzed whole narrative passages, or sections of interview transcripts in which participants were describing an event. Based on Ricoeur's (1984) descriptions of the three types of preunderstandings that influence narrative configuration - structural, symbolic, and temporal elements - I developed questions to target each of these preunderstandings. The questions I used in my analysis of narratives are listed in Table 1. I used the questions I developed from Ricoeur (1984) to tease apart the structural 
Table 1. Questions for data analysis to address Ricoeur's (1984) elements of preunderstandings.

\begin{tabular}{|c|c|}
\hline Element & Question \\
\hline \multicolumn{2}{|c|}{ Structural elements } \\
\hline Goals & What does the narrator/agent want to do? \\
\hline Agents & With whom or what is the narrator interacting? \\
\hline Motives & Why does the narrator/agent want to do $[\mathrm{x}]$ ? \\
\hline Circumstances & What conditions does the narrator/agent describe? \\
\hline Interactions & What events transpire between the narrator and others? \\
\hline Outcome & What does the narrator do? What happens to the narrator? \\
\hline \multicolumn{2}{|c|}{ Symbolic elements/cultural understandings } \\
\hline Evaluation & How does the narrator evaluate people or events? \\
\hline Foundation & What basis is the narrator using to make evaluative comments? \\
\hline \multicolumn{2}{|l|}{ Temporality } \\
\hline & How do narrators order events? \\
\hline & What words do they use to describe events related in time? \\
\hline
\end{tabular}

and temporal elements of their narratives from the symbolic elements, or cultural understandings, they were drawing on in evaluating their experiences. Using the data analysis questions from Table 1, I distinguished the elements of the narrative from each other and identified pieces that answered multiple data analysis questions. In this article, I will distinguish between the three main elements of Ricoeur's (1984) preunderstandings using changes to the font as shown below:

- Structural elements in italics.

- Symbolic elements/cultural understandings in bold.

- $\underline{\text { Temporal elements underlined. }}$

I identified narrative passages in which participants described events related to persistence or positioning using constant comparative coding methods (Charmaz, 2006). These narrative passages were compiled and analyzed first by participant. I re-read through the narratives, color-coded narratives using the data analysis questions, and then wrote up initial interpretations of each narrative by participant. These written initial interpretations served to describe the context for the events and highlight the cultural understandings that each participant used in making meaning of those events. These initial interpretations were also a space for me to begin to think about the explicit use of cultural understandings and what implicit understandings were at work as well.

After analyzing the persistence and positioning narratives by participant, I identified common cultural understandings that were in use across participants. I then grouped the narrative passages by these common cultural understandings, and analyzed and re-interpreted each narrative passage again in relation to the common cultural understanding. In presenting the results, I included whole narrative passages from the interview transcripts because these passages include the structural and temporal elements of the narratives that are necessary to understand the symbolic elements or cultural understandings that participants were using to evaluate the experiences they described. 


\section{Analysis example}

As participants described events in their lives, they configured narratives in which they referred to symbolic preunderstandings - cultural understandings - that were available in the broader societal context to explain and evaluate their experiences. In this section, I present a narrative from one participant, Judy, as an example of how I used the data analysis questions in Table 1 to analyze a narrative from an interview transcript. In this article, to distinguish between Ricoeur's preunderstandings, I used changes to the font, such as structural elements in italics, symbolic elements/ cultural understandings in bold, and temporal elements underlined.

\section{Judy's narrative}

Judy's academic goal was to graduate from college and go to medical school. There were no high school graduates in Judy's family and her parents worked in low-wage jobs in construction and food service. Judy told narratives about being positioned as someone who would not graduate and would not go to medical school because of her family background. She talked about feeling "empowered" because she had proven other people's expectations wrong in graduating from high school and being about to graduate from college, but she also struggled as she got closer to her college graduation and closer to applying to medical school. Judy said that these struggles made her feel empowered by moving beyond the doubters' expectations, but she continued to explain her struggles in terms of resisting something else that she was supposed to be (i.e. reproducing her born-into social position).

In this data example from Judy, she discussed why she did not feel strong because she felt as if she was struggling to meet her academic goals, while her peers seemed to succeed more easily than she did. Judy's family members supported her persistence toward her academic goals, even though they could not help her financially or with advice. Judy admitted that they did provide her with much needed encouragement:

My mom and my brother because even though they don't know what college is about or anything about what I'm doing educational wise, like they wouldn't know anything about what I'm doing, but as a person they know me and they know I'm not a quitter and they push me and push me and push me and push me to do better. And I tell them, I go to them and complain and tell them what's going on, you know "I can't do this" and "it's just too hard" and they push me and they say "You know what? You've been through harder just in life's journeys, you know? You've been through more than a 50 year-old woman has. Don't sit here and say that this stupid class is holding you back from your life, from your dreams that you've been dreaming about since you were a little girl." And that is what motivates me and pushes me to go on and no matter, even if I do fail the class, I feel I know in my self I tried and I worked my hardest to keep going. And you know I might not have a 3.0 or 3.5 or whatever, but I know that the grades that I have, the grades that are on my transcripts, I worked my ass off for, and coming from where I came from that's fantastic. So a lot of times I don't remember that and I don't think about that and they help me to remember like, "Don't compare yourself to them because they haven't been through the stuff that you've been through, and if they ever were to go through it, they wouldn't survive, they wouldn't make it" and I guess that's kind of like what keeps me going, like just motivates me to just keep going one day at a time. Even if it is one day at a time, might have 20 tests coming up but it's one dav at a time, you know, and I can only do as much as I try to do in one day ... I mean it's just feels like a lot of times I put in my head, I'm like okay I need that B, I just need the B, I mean not even an A, just give me 
a B, just the B, just the B, you know? And I don't get it. And then in my mind I'm like, why? Like I can't even get a B, and it's just like...it's really hard for me as a person to set a goal and not achieve it. It's so hard 'cause I'm just like such a goal oriented person...I' $\underline{m}$ just like this $\underline{\text { s }}$ my goal and I'm going to reach it and by God I will die trying to reach that goal, you know what I'm saying? And so for me to give up any goal, you know, any thing from a little "I'm going to run a mile" to like "I'm going to be the president," you know what I'm saying? Like anything, it's hard...it literally puts me into depressed mode like, why am I even here? I might as well just give up. Why do I still live if I can't even do this? You know what I'm saying? Like why did you give me the motivation to be a doctor if I'm too stupid to even get this freakin' test? Like it puts me like down, like very down to the point where I'm like ... I'm done, like I'm done with trying, I'm done with working my ass off to get where I need to be and it doesn't work, like it's that hard for me: to set a goal and not reach it. (Judy, I-2)

\section{Structural elements}

In this paper, the whole narrative passage is in italics because it all represents the structural (linguistic) elements of a narrative. In practice, I highlighted the different structural elements in different colors for a more nuanced analysis in order to distinguish between the different structural elements of Judy's and others' narratives. In this paper, I will use the language of the structural elements in describing how I went about the analysis. Judy's goal is to graduate from college and apply to medical school to become a doctor. Ultimately, her goal is to be happy, and she equates her goal to graduate from college, go to medical school, and become a doctor as the only way in which she will be happy. There are three different groups of people, or agents, in this narrative: Judy, her family (mother and brother), and her peers in college. Her family encourages her to stay persistent in pursuing her academic goals (dreams) and to not compare herself with others, but to remember what she has had to overcome to reach her current position (on the eve of her college graduation). The circumstances and interactions that Judy describes in this narrative are that she feels emotionally supported by her family to stay persistent, but her lower grades (in comparison to her peers) remind her that even if she is working hard toward her goals, she may not end up being accepted into medical school. The outcome of the narrative is this impending feeling of not reaching her goals, which leaves Judy feeling depressed and like her happiness (tied to reaching her goals) is out of her reach.

\section{Temporal elements}

When analyzing narratives for temporal elements, I looked at both verb tense and time-related words that participants used. In terms of verb tense, some of Judy's narrative includes references to things that have happened in the past - "I tried and I worked my hardest" and "I worked my ass off" - as indicated by the past tense of the verbs try and work. Both phrases - "You've been through harder" and "they haven't been through the stuff that you've been through" - indicate that Judy experienced something in the past that she is no longer experiencing in the present. "Your dreams that you've been dreaming about since you were a little girl" is a phrase that contains a time-related word (since) and indicates that her dreams existed in the past and continue to exist in the present.

Judy's discussion of past events in her use of past tense verbs does not dominate the narrative, however; her use of present tense verbs does. She describes the 
support that her family gives her and the results of that support as an on-going context in the present tense: "they push me," "I tell them," "I go to them," "I complain," "they push me," and their support "motivates me and pushes me to go on." Judy discusses her grades in the present tense: "I might not have a 3.0 or 3.5 or whatever, but I know the grades that I have," and how she wants "just the B, you know? And I don't get it." She describes her present conditions: "it's really hard for me as a person to set a goal and not achieve it" and "it literally puts me into depressed mode." She describes herself in the present tense: "I'm not a quitter" and "I'm such a goal-oriented person," but also "I'm too stupid."

When Judy discusses her expectations for the future, she says: "this is my goal and I'm going to reach it and by God I will die trying to reach that goal." Yet, she describes her present state of mind that contradicts what she refers to happening in the future: "I'm done" and "I'm done with working my ass off to get where I need to be and it doesn't work." Judy's narration of her experiences indicates that while she is thinking about the influence of the past (memories) and her future expectations, she is clearly focused on her experience of the present.

\section{Symbolic elements}

In this narrative, Judy makes evaluative statements about herself, others, and events in her experience that helped me to identify the foundation for these statements, which would represent the symbolic elements. For example, when she evaluates herself, she uses the present tense: "I'm not a quitter" and "I'm such a goal-oriented person," but also "I'm too stupid." She evaluates her mother and brother - "they wouldn't know anything about what I'm doing" - using the foundation for this evaluation that neither her mother nor her brother have graduated from high school or attend college.

She also reiterates or retells her mother's and/or brother's evaluations of her peers, peers who are not the first in their families to go to college: "Don't compare yourself to them because they haven't been through the stuff that you've been through, and if they ever were to go through it, they wouldn't survive, they wouldn't make it." This retelling of the evaluation of her peers is significant because this evaluation (and the implicit foundation for the evaluation) is what "motivates" Judy to be persistent in working toward her goals. So what is the foundation - or cultural understanding - that Judy is implicitly using to evaluate her peers as successful but not as strong as she is? Looking at other evaluative comments and the foundations for those can be helpful in analyzing this statement, such as "I worked my ass off for, and coming from where I came from that's fantastic." Where she came from is a family of low socioeconomic means with little education. How is she not still where she came from? She worked hard. Judy reiterates this in different sections of the narrative: "I tried," "I worked my hardest," and "working my ass off."

\section{Developing interpretations}

After using the data analysis questions from Ricoeur to analyze narratives in this way, I wrote initial interpretations of the narratives by participant. I analyzed all of Judy's narratives first, wrote each initial interpretation as I analyzed it, comparing the symbolic resources, or cultural meanings, that she was using as foundations for her evaluations. Then I compiled and compared the cultural meanings in use by all 
participants and chose the ones most prevalently used. I then used the most prevalent cultural meanings across participants (school as a competition, pull-yourself-upby-your-bootstraps, and school as a meritocracy) in reinterpreting each participant's narratives (e.g. see Wilson \& Kittleson, 2013).

For example, in the narrative above, Judy's insistence on her effort (hard work) was the foundation she was using to evaluate her experience of needing to stay motivated when she did not compete well with her peers academically. If her hard work was not helping her reach her goals of college graduation and attendance to medical school, then the pull-yourself-up-by-your-bootstraps cultural understanding - academic success through individual hard work - that was helping her to feel persistent stopped becoming useful. Judy was left with feeling as if she did not have merit (school as a meritocracy) to compete with her peers (school as a competition). This was the conclusion due to a reinterpretation from this narrative based on the data analysis questions in Table 1 and using the common cultural meanings across participants.

\section{Discussion}

While there is no room for more examples to demonstrate the usefulness of this method of data analysis of narratives, I will use my own experience with this method to discuss how it is useful (1) in identifying cultural meanings that become resources for participants' positioning work, (2) in grounding the identified cultural meanings in participants' experiences, and (3) in understanding participants' interpretations of constraint and agency within that context.

\section{Identifying cultural meanings across participants}

In looking for how the participants' narratives were constructed and the interactions between the three major elements of preunderstandings, I was able to tease out the symbolic resources from the temporal and structural elements of their narratives. By identifying their evaluative comments of the structural elements (goals, agents, circumstances, outcomes, etc.), I then could look for the ideas they were using to support their evaluations and see if the participants were using similar ideas in other narratives. If these ideas used for evaluations were consistently referred to within their narratives and were ideas used to explain their experiences as students and science majors, they were listed as a possibility for a cultural meaning. The list of possible cultural meanings compiled after initial interpretations of all participants' narratives was then analyzed to look for common cultural meanings that could be considered as available in their 'figured world' (cultural context) and used for interpretation. For example, in the larger study, there were three cultural meanings in use by all participants: school as a competition, pull-yourself-up-by-your-bootstraps, and school as a meritocracy. These cultural meanings were then used as foundations for reinterpreting participants' narratives to look for explicit and implicit uses by participants (Wilson \& Kittleson, 2013).

\section{Grounding cultural meanings in participants' experiences}

As an interpretive researcher, I consistently reflected on the basis for my interpretations - am I pulling ideas from my subjectivities, from the research literature, or are 
these interpretations really grounded in the lives of my participants and what is meaningful to them? In developing data analysis questions using Ricoeur's (1984) preunderstandings, I was able to create a heuristic that helped me to keep my interpretations grounded in the participants' narratives. These data analysis questions aided me in thinking about the cultural understandings that the participants were using in their narratives to make sense of the events they described. As a tool for data analysis, these questions helped me to focus on the participants' interpretation of the events in the narratives alongside my interpretations of their experiences. As a result, I felt better able to create a situation for data analysis in which as a researcher, I was in a dialogue between my interpretations and the participants' interpretations about their persistence and the positioning events they described. The questions as a heuristic helped me to keep track of how I was analyzing participants' narratives so that when I stepped away from analysis and came back to it at a later time, I could better keep track of what data I was using in my interpretations of narratives. In addition, the questions as a heuristic aided my reflections of how my interpretations were grounded (in the data, in research literature, and/or my subjectivities).

For example, the participants consistently referred to the idea that if someone works hard, no matter what part of society they come from, they should be able to accomplish their goals. While I named this cultural meaning pull-yourself-up-byyour-bootstraps, what it meant for participants is based on their discussion of their experiences as first-generation college students and science majors. I did not begin analysis looking for this idea, but in analyzing their narratives, found the idea of independent hard work to be a significant influence and consistently used by participants in evaluating their own and others' persistence.

\section{Understanding participants' interpretations of constraint and agency}

Ricoeur's ideas about narrative construction helped me to think about the use of cultural meanings in how the narrator positions him/herself and others and the impact on feelings of structure and agency. After compiling the common cultural meanings in use, I was able to compare the uses of these preunderstandings across participants. For example, the pull-yourself-up-by-your-bootstraps meaning helped many of the participants feel in control of their persistence toward their goals because the idea is based on independent hard work or effort. In contrast, however, Judy was consistently unable to use the cultural meaning of pull-yourself-up-by-your-bootstraps to explain her experience. When Judy felt that pull-yourself-up-by-your-bootstraps had failed to explain her lack of academic success, then her "failure" to persist or to feel persistent was equated to her lack of merit. She referred to other possibilities, such as the cultural meaning of school as a meritocracy, which when she used alone, left her feeling "stupid."

Thinking about the alternative meanings that participants use or refer to when the prevailing cultural meaning in use by other participants fails them, allows us to think about how participants assent to or resist certain cultural ideas. If you position yourself as a non-competitor due to lack of merit, then your agency to change your position is constrained. In contrast, if you position yourself as a competitor (or noncompetitor) based on your effort (or lack of effort), then your agency to change your position is in your control. While Judy has used pull-yourself-up-by-your-bootstraps to explain some of her experiences, and thus assents to this idea as a way to evaluate 
her experience, in other instances, she finds that its explanatory power is lacking. Thus, in her narrative she can use her experience to contradict this meaning, and, even if it is just in the telling of her narrative, resist its significance.

\section{Conclusion}

The purpose of this paper was to show how Ricoeur's (1984, 1988, 1992) writings on the configuration of narratives and the implications for positioning and narrative identity are useful to qualitative researchers (1) in identifying cultural meanings that become resources for participants' positioning work, (2) in grounding the identified cultural meanings in participants' lived experiences, and (3) in understanding participants' interpretations of constraint and agency within that context. By starting with the consistency between the philosophical hermeneutics of Ricoeur $(1984,1992)$ and sociocultural theorists interested in positioning events and identity (Holland et al., 1998; Holland \& Leander, 2004; Levinson \& Holland, 1996; Sfard \& Prusak, 2005; Verhesschen, 2003), I provided an argument for their conceptual consistency. In addition, I discussed how I developed a data analysis heuristic from Ricoeur's (1984) preunderstandings in the configuration of narratives to answer research questions aimed at understanding participants' use of cultural resources in their interpretations of their experiences. In describing my data analysis process with an example narrative, I aimed to be transparent about how I moved from the data to my interpretations and conclusions about the power of these cultural meanings for participants, as well as how they position themselves on the basis of those interpretations. Therefore, this paper is meant to provide other researchers with narrative data with a strategy to explore cultural meanings within their participants' contexts.

These cultural meanings, while interpretively powerful, were true only in as much as they helped participants, and myself, explain or evaluate their life experiences. Using ideas from the philosophical hermeneutics of Ricoeur allowed me to explore how context shapes the narratives of participants of their lived experiences by looking at how they made meaning and responded to cultural meanings:

When we are in the role of hearers or readers of the narrative experiences - the creations - of others, we understand the stories through the linguistic processes we use in constructing our own narratives. We call this kind of understanding - of hearing the meaning of a story - hermeneutic understanding. (Polkinghorne, 1988, p. 160)

Hermeneutic understanding is a product of a research process that shapes not only the readers' understanding, but the researchers' understanding of themselves (Schwandt, 2004). Therefore, my research process of interviewing and analyzing the narratives of female first-generation students has resulted in my presentation of the interpretations of meanings that are salient for these women, interpretations that I - as the researcher - find meaningful when thinking about cultural issues that are considered important in analyzing personal learning experiences in science education, as well as a new understanding of the figured world of academic science and myself.

\section{Acknowledgements}

Many thanks go to Melissa Freeman for her encouragement and help in conceptualizing this manuscript. Thanks also to the members of my writing group who have helped me through the process of preparing this manuscript. 


\section{Notes on contributor}

Rachel E. Wilson is an assistant professor at the Reich College of Education, Appalachian State University, USA. Her research interests are in cultural influences on learning and personal learning experiences, with specific emphasis on science learning. In addition to studies of the persistence of undergraduate female science majors, her current research examines preservice teachers' experiences learning science through service-learning experiences.

\section{References}

Austin, H., \& Carpenter, L. (2008). Troubled, troublesome, troubling mothers: The dilemma of different in women's personal motherhood narratives. Narrative Inquiry, 18, 378-392.

Bartlett, L. (2007). Literacy, speech and shame: The cultural politics of literacy and language in Brazil. International Journal of Qualitative Studies in Education, 20, 547-563.

Carlone, H. B. (2004). The cultural production of science in reform-based physics: Girls' access, participation, and resistance. Journal of Research in Science Teaching, 41, 392414.

Charmaz, K. (2006). Constructing grounded theory: A practical guide through qualitative analysis. Los Angeles, CA: Sage.

Eisenhart, M. (2001). Educational ethnography past, present, and future: Ideas to think with. Educational Researcher, 30(8), 16-27.

Ezzy, D. (1998a). Theorizing narrative identity: Symbolic interactionism and hermeneutics. The Sociological Quarterly, 39, 239-252.

Ezzy, D. (1998b). Lived experience and interpretation in narrative theory: Experiences of living with HIV/AIDS. Qualitative Sociology, 21, 169-179.

Ezzy, D. (2000). Fate and agency in job loss narratives. Qualitative Sociology, 23, 121-134.

Freeman, M. (2007). Performing the event of understanding in hermeneutic conversations with narrative texts. Qualitative Inquiry, 13, 925-944.

Gee, J. P. (1999). An introduction to discourse analysis. New York, NY: Routledge.

Gee, J. P. (2001). Identity as an analytic lens for research in education. Review of Research in Education, 25, 99-125.

Geertz, C. (1973). The interpretation of cultures. New York, NY: Basic Books.

Grondin, J. (1994). Introduction to philosophical hermeneutics. (J. Weinsheimer, Trans.). New Haven, CT: Yale University Press.

Hole, R. (2007). Narratives of identity: A poststructural analysis of three deaf women's life stories. Narrative Inquiry, 17, 259-278.

Holland, D. C., Lachicotte, W. J., Skinner, D., \& Cain, C. (1998). Identity and agency in cultural worlds. Cambridge, MA: Harvard University Press.

Holland, D., \& Leander, K. (2004). Ethnographic studies of positioning and subjectivity: An introduction. Ethos, 32, 127-139.

Johnson, A. (2007). Unintended consequences: How science professors discourage women of color. Science \& Education, 91, 805-821.

Jupp, J. C., \& Slattery, P. (2010). White male teachers on difference: Narratives of contact and tensions. International Journal of Qualitative Studies in Education, 23, 199-215.

Levinson, B. A., \& Holland, D. (1996). The cultural production of the educated person: An introduction. In B. A. Levinson, D. E. Foley, \& D. C. Holland (Eds.), The cultural production of the educated person: Critical ethnographies of schooling and local practices (pp. 1-54). Albany, NY: State University of New York Press.

Niesz, T. (2008). Professional movements, local appropriations, and the limits of educational critique: The cultural production of mixed messages at an urban middle school. International Journal of Qualitative Studies in Education, 21, 327-346.

Orbe, M. P. (2004). Negotiating multiple identities within multiple frames: An analysis of first-generation college students. Communication Education, 53, 131-149.

Polkinghorne, D. E. (1988). Narrative knowing and the human sciences. Albany, NY: State University of New York Press.

Polkinghorne, D. E. (1995). Narrative configuration in qualitative analysis. In R. Wisniewski \& J. A. Hatch (Eds.), Life history and narrative (pp. 5-23). Washington, DC: Falmer. 
Ricoeur, P. (1984). Time and narrative, Vol. I. (K. McLaughlin and D. Pellauer, Trans.). Chicago, IL: The University of Chicago Press.

Ricoeur, P. (1988). Time and narrative, Vol. III. (K. McLaughlin and D. Pellauer, Trans.). Chicago, IL: The University of Chicago Press.

Ricoeur, P. (1992). Oneself as another. (K. Blamey, Trans.). Chicago, IL: The University of Chicago Press.

Schwandt, T. A. (2004). Hermeneutics: A poetics of inquiry versus a methodology for research. In H. Piper \& I. Stronach (Eds.), Educational research: Difference and diversity (pp. 31-44). Burlington, VT: Ashgate.

Seidman, I. (2006). Interviewing as qualitative research: A guide for researchers in education and the social sciences (3rd ed.). New York, NY: Teachers College Press.

Sfard, A., \& Prusak, A. (2005). Telling identities: In search of an analytic tool for investigating learning as culturally shaped activity. Educational Researcher, 34(4), 14-22.

Stuber, J. M. (2011). Integrated, marginal, and resilient: Race, class, and the diverse experiences of white first-generation college students. International Journal of Qualitative Studies in Education, 24, 117-136.

Verhesschen, P. (2003). 'The poem's invitation': Ricoeur's concept of mimesis and its consequences for narrative educational research. Journal of Philosophy of Education, 37, 449465.

Wilson, R. E., \& Kittleson, J. M. (2013). Science as a classed and gendered endeavor: Persistence of two white female first-generation college students within an undergraduate science context. Journal of Research in Science Teaching, 50, 802-825. 